\title{
Associação Cruzeiro Jaguarense em Jaguarão RS (1881-2016): Entre a História e a Memória
}

\author{
Asociación Cruzeiro Jaguarense en Jaguarão RS (1881-2016): Entre la
}

Historia y La Memoria

Case Study of Associação Cruzeiro Jaguarense In Jaguarão (1881-2016): Between History of Memory

\author{
Alan Dutra de Melo ${ }^{1}$ \\ Ronaldo Bernardino Colvero ${ }^{2}$
}

\begin{abstract}
Resumo
O estudo em questão faz parte da tese em andamento, desenvolvida no Curso de Pós-Graduação em Memória Social e Patrimônio Cultural, vinculado à Universidade Federal de Pelotas, sobre a Associação Cruzeiro Jaguarense, situada em Jaguarão, mais conhecida como Clube Jaguarense, cuja sede central está localizada no centro da cidade, dentro do perímetro da zona de tombamento realizado pelo Instituto do Patrimônio Histórico e Artístico Nacional (IPHAN) e que encontra-se desde 2011 interditado devido a queda da cobertura, que embora recomposta não possibilitou o seu uso pleno. Trata-se de exemplar identificado pelo órgão mencionado como de proteção rigorosa. O objetivo do estudo é compreender a importância do clube para a cidade à partir da metodologia do estudo que é de natureza interdisciplinar com enfoque qualitativo, utilizando como fonte principal os jornais à partir do século XIX e entrevistas realizada com pessoas com vinculação a entidade. Os resultados, apontam para a importância do bem cultural, destacando a materialidade como suporte de memória. As memórias, por sua vez, são associadas ao bem associadas ao bem como integrantes do patrimônio imaterial da entidade. Além disso, o estudo revelou vínculos com a história, especialmente no final do século XIX, durante a suas origens como Club Jaguarense, fundado em 1881.
\end{abstract}

Palavras-Chave: Associação Cruzeiro Jaguarense; História; Jaguarão; Memória.

\section{Resumen}

El estudio en cuestión forma parte de la tesis en marcha, desarrollada en el Curso de Postgrado en Memoria Social y Patrimonio Cultural, vinculado a la Universidad Federal de Pelotas, sobre la Asociación Cruzeiro Jaguarense, situada en Jaguarão, más conocida como Club Jaguarense, cuya sede que se encuentra en el centro de la ciudad, dentro del perímetro de la zona de patrimonio reconocido por el Instituto del Patrimonio Histórico y Artístico Nacional (IPHAN) y que se encuentra desde 2011, cerrado, debido a la caída de la cobertura, que aunque recompuesta no posibilitó su uso pleno. Se trata de un ejemplar identificado por el órgano mencionado

\footnotetext{
${ }^{1}$ (Doutorando e Mestre em Memória Social e Patrimônio Cultural UFPEL/ Universidade Federal de Pelotas Pelotas RS/ Professor da Universidade Federal do Pampa Jaguarão - Cursos de Bacharelado em Produção e Política Cultural e Tecnologia de Gestão em Turismo; Jaguarão, Rio Grande do Sul, Brasil; alandutrademelo@gmail.com).

2 (Doutor em História PUC RS; Professor Universidade Federal de Pelotas RS; Professor Universidade Federal do Pampa/ São Borja, Rio Grande do Sul, Brasil ; rbcolvero@gmail).

Trabalho apresentado no III Encontro Humanístico Multidisciplinar e II Congresso Latino-Americano em Estudos Humanísticos Multidisciplinares, Jaguarão/RS, Brasil, 2017.
} 
como de protección rigurosa. El objetivo del estudio es comprender la importancia del club para la ciudad a partir de la metodología del estudio que es de naturaleza interdisciplinaria con enfoque cualitativo.Los resultados, ya en fase de conclusión, apuntan a la importancia del bien cultural, destacando la materialidad como soporte de memoria. Las memorias, a su vez, se asocian al bien asociadas al bien como integrantes del patrimonio inmaterial de la entidad. Además, el estudio reveló vínculos con la historia, especialmente a finales del siglo XIX, durante sus orígenes como Club Jaguarense, fundado en 1881.

Palabras claves: Asociación Crucero Jaguarense; Historia;Jaguarão; Memoria.

\begin{abstract}
This article is related to a doctoral dissertation being completed in the graduate program in Social Memory and Cultural Heritage at the Federal University of Pelotas. The dissertation examines a recreational association, "Club Jaguarense", founded in the year 1881 in the city of Jaguarão in the southern Brazilian state of Rio Grande do Sul. The article problematizes its recent declaration as an official cultural heritage site. This was carried out employing its current name "Associação Cruzeiro Jaguarense", a name that was adopted when the association fused with a local soccer team, Esporte Clube Cruzeiro do Sul, in 1975. The problem that proompted this study stems from the events of November 2nd, 2011 in which the roof of the association's headquarters collapsed and had to undergo emergency repairs funded by the Instituto do Patrimônio Histórico e Artístico Nacional (National Historical and Artistic Heritage Institute). The methodology employed entails research of documentary primary sources of the Associação Cruzeiros Jaguarense, as well as newspapers, and oral history. The results point to the cultural relevance of the property in question bettween history of memory.
\end{abstract}

Keywords: Associação Cruzeiro Jaguarense; Cultural heritage; Jaguarão; Memory.

\title{
1. Introdução
}

O presente trabalho problematiza a Associação Cruzeiro Jaguarense, reconhecida comumente como Clube Jaguarense, pois sua sede principal é a mesma desde o final do século XIX. O interesse em pesquisar sobre esta entidade refere-se a sua importância para o município de Jaguarão, situado no Rio Grande do Sul (RS), Brasil, tendo em vista o seu valor como patrimônio cultural.

E sobre os primórdios da ocupação deste município como ponto de expansão da Monarquia Portuguesa e contenção da Coroa Espanhola, trazemos o elaborado por Custódio et al. (2009):

Pelo Tratado de Santo Ildefonso (1777) as terras que hoje integram o município pertenciam à Coroa Espanhola, mas ausência de limites precisos provocou uma sucessão de disputas com Portugal. Apoiados na Vila de São Pedro do Rio Grande, desde 1789, a concessão de sesmarias na região era prática corrente pelas autoridades lusitanas, afrontando o domínio espanhol. Para frear o avanço português, os espanhóis fundaram pequenos postos de guarda ao norte do Rio Jaguarão (1792). Um deles, a Guarda da Lagoa e do Cerrito, se situava aonde mais tarde se desenvolveu a cidade de Jaguarão. No entanto, estes precários estabelecimentos militares não foram capazes de impedir a expansão dos sesmeiros (CUSTÓDIO et al., 2009, p. 69).

No estudo elaborado como Dossiê para Tombamento realizado pelo Instituto do Patrimônio Histórico e Artístico Nacional (IPHAN) no município em questão, acresce-se dados sobre os sesmeiros: 
Existem diversos levantamentos sobre a origem dos sesmeiros que requereram terras na região, através da qual se constatou que, estes eram, em sua maioria, provenientes de Portugal, e tinham como principais atividades o comércio e as funções militares, e possivelmente muitos desses proprietários participaram das constantes disputas fronteiriças entre as coroas ibéricas (DOSSIÊ PARA TOMBAMENTO DE JAGUARÃO, 2010, p. 85).

Retomando o elaborado por Custódio et al. (2009) acerca da ocupação deste território na fronteira que, mais tarde, constituiu-se como a cidade de Jaguarão, temos:

A eclosão de uma guerra entre Portugal e Espanha (1801) motivou os portugueses a expandir seus domínios no sul do Brasil, o que resultou a apropriação da faixa territorial entre os rios Jaguarão e Piratini, nos Campos Neutrais (...). Em 1802 o Coronel Manoel Marques de Souza ocupou a Guarda do Cerrito foi logo transformada em posto militar permanente pelo Sargento-Major Vasco Pinto Bandeira, que também era grande estancieiro, proprietário de fazendas e de escravos (CUSTÓDIO et al., 2009, p. 69).

Do ano de 1802, quando foi instalada a Guarda Militar do Cerrito, permaneceu até 31 de janeiro de 1812, quando foi elevada para freguesia, através de Resolução Régia do Príncipe Regente, denominada freguesia do "Espírito Santo do Cerrito de Jaguarão", período em que pertencia à Rio Grande (Cf. Custódio et al., 2009). Na explicação do autor citado, ocorreu uma disputa legal pela posse da "Estância Real do Cerrito", imensa área doada pela Coroa Portuguesa à Baronesa de Majé que estava ocupada por invasores e arrendatários, sendo esta questão resolvida com retorno da proprietária à Portugal e decisão em ação favorável aos moradores da localidade.

E mais tarde, em 1832, durante o período regencial, passou à Vila com a denominação de Divino Espírito Santo do Cerrito. Conforme relato de Miranda (2000), este período foi qualificado pelo autor como "Fronteira viva e de acumulação: Jaguarão de vila (1832) a cidade (1855)", "Dez anos após a independência do Brasil, em 6 de julho de 1832, uma Lei Imperial criava a vila de Jaguarão que por sua vez, tinha sob sua incumbência administrativa os atuais municípios de Arroio Grande, Herval e Piratini” (p. 174). Nesse processo, foi empossada, segundo Custódio et al. (2009), na Vila de Jaguarão, em 1833, a primeira Câmara de Vereadores, e sua população já ultrapassava 5.000 habitantes.

Posteriormente, em 1855, recebe autonomia por Lei Provincial n. 322, sob o segundo reinado, elevando-se à cidade, com publicação realizada no dia 23 de novembro. Sobre essa emancipação Enlsslin (2007) escreve,

Nesse período existiam apenas 4 cidades reconhecidas na província: Porto Alegre, Rio Grande, Pelotas e Rio Pardo. Jaguarão foi elevada a cidade no dia 21 de 
novembro de 1855, sendo a quinta cidade do estado, mas as comemorações foram no ano seguinte, devido à trágica epidemia de cólera que assombrou a população (ENLSSLIN, 2007, p. 46).

Tratando-se, então, do município de Jaguarão, o Clube Jaguarense, foco deste estudo, pode ser considerado ao longo do tempo um espaço de sociabilidade importante para a elite. Em seus primórdios, temos, especificamente em 1852, a fundação da Sociedade Recreação Familiar Jaguarense, como sociedade bailante. Há indicações do início da entidade datada em 1857, mas a partir da descoberta de novos documentos, feitos por nós, foi possível lançarmos a fundação da associação em tempo anterior. E sobre a relação neste espaço de sociabilidade cabe citarmos, também, que Manuel Pereira Vargas foi presidente da Bailante no ano de 1857, considerado o principal comandante durante a invasão dos blancos em Jaguarão em 1865. Portanto, fica evidenciada a importância da Sociedade na época e sua relação com os estratos sociais que estavam em situação de comando naquele período - sobre o contexto populacional, vejamos abaixo:

Em 1858 Jaguarão já contaria com 5722 habitantes, dos quais 3673 livres, 86 libertos e 1963 cativos. Observa-se assim que, mesmo com o final do tráfico em 1850 e a venda de cativos para as fazendas de café em São Paulo e Rio de Janeiro, o número de trabalhadores escravizados em Jaguarão continuava significativo, sobretudo na área rural, possivelmente em virtude do aumento na produção das charqueadas para atender à crescente demanda por alimentação para os escravos das lavouras cafeicultoras do sudeste, para onde a maior parte da produção era exportada. Por outro lado, na área urbana de Jaguarão, a quantidade de cativos diminuiu (DOSSIÊ PARA TOMBAMENTO DE JAGUARÃO, 2010, p. 127).

Cabe retomarmos ainda que, o município de Jaguarão, está localizado em zona de fronteira, sendo um território belicoso durante o período colonial em suas primeiras décadas, e mais tarde, no período imperial, tiveram conflitos envolvendo Brasil, Uruguai, Argentina e Paraguai, que culminaram,no final do século XIX, com a Guerra do Paraguai (1864-1870). Tratava-se, sobretudo, de um território militarizado.

Sobre um conflito emblemático na história do município, precisamente, em 27 de janeiro de 1865, com a invasão dos blancos uruguaios que tomaram-o a força, mas foram expulsos pelos brasileiros mesmo com condições adversas, e pela reconhecida bravura de sua população, recebeu a denominação imperial de cidade heroica. $\mathrm{O}$ fato citado corroborou para a visita militar à cidade de Luiz Felipe Maria Fernando de Gastão, o Conde D`Eu ${ }^{3}$, Príncipe casado com a Princesa Isabel, que ao passar em Jaguarão no ano de 1865, deixou impressões:

\footnotetext{
${ }^{3}$ Uma rua do município de Jaguarão, a atual Vinte de Setembro, já foi outrora denominada como Rua Conde D’Eu. O estudo em questão identificou mudanças de nomes do período imperial, dando relevo no espaço público
} 
Pareceu-me Jaguarão uma cidade relativamente insignificante. Está situada na margem esquerda do rio do mesmo nome, que, como se sabe, aqui forma a fronteira com o Estado Oriental. À roda da cidade veem-se, irregularmente disseminados, princípios de fortificações guarnecidas de algumas peças de artilharia. Quer fosse em virtude destes imperfeitos meios de defesa, quer em consequência da enérgica atitude que tomou a Guarda Nacional, Jaguarão escapou, a 27 de janeiro deste ano, de ser saqueada pelos "blancos". Um bando deles chegou a passar o rio e devastou diferentes estâncias vizinhas. Pode-se dizer que deram a volta à roda da cidade; depois julgaram mais prudente tornar a passar a fronteira. Em frente de Jaguarão, na margem direita do rio, ergue-se a pequena cidade oriental de San Servando. Está ligada com Montevidéu por um serviço regular de diligências que chegam um dia sim, um dia não, e fazem a viagem em quatro dias. Jaguarão é o ponto mais austral que em nossa viagem atingimos. Fica situado cerca de $1^{\circ}$ mais ao Sul que o Rio Grande, e mais $5^{\circ}$ que Porto Alegre ou Uruguaiana. Não é, todavia, o ponto mais austral do Brasil, o qual ainda se estende mais $1^{\circ}$ para o Sul. O Jaguarão forma fronteira até a sua foz na lagoa Mirim. Esta lagoa forma como que um mesmo sistema com a lagoa dos Patos [grifo do autor] (CONDE D’EU,1936, p. 209).

Do exposto, fica evidenciada a fronteira como espaço de tensão, portanto, ainda dentro das turbulências do século XIX, em que Jaguarão foi ponto estratégico dessas relações resultando na manutenção da fronteira para a expansão do Brasil meridional. Sobre o contexto da tomada realizada pelos blancos uruguaios no dia 27 de janeiro, melhor situa Rizzon (s.d), apontando que o ato foi uma retaliação ao cerco de Paissandu no Uruguai, do qual o Brasil fazia parte.

Acontecimentos do final de 1864, na cidade uruguaia de Paissandu, e de janeiro de 1865, em Jaguarão, estão diretamente relacionados. No ano de 1864, o caudilho uruguaio do partido colorado Venancio Flores, que estava exilado na Argentina, invade com o seu exército o Uruguai e, depois de tomar a cidade de Salto, sitia a cidade de Paissandu, às margens do Rio Uruguai. Venancio Flores contou com o apoio do presidente argentino, o general Bartolomé Mitre, que julgava oportuno derrubar um governo simpático aos seus opositores federalistas, e com a cumplicidade do Império de Dom Pedro II, comprometido com os interesses dos brasileiros que viviam nos campos uruguaios e que estavam ameaçados de expulsão do Uruguai pelo governo dos blancos [...] Dessa forma, Venancio Flores pôde reunir ao seu lado 16.000 soldados dos exércitos de três nações para enfrentar cerca de 700 homens que defendiam Paissandu. A historiografia uruguaia costuma colocar o cerco a Paissandu no plano da disputa entre blancos e colorados, minimizando o componente dos interesses estrangeiros. Já na historiografia brasileira, o mesmo acontecimento faz parte do preâmbulo da Guerra do Paraguai, o que justifica a intervenção do Império no território uruguaio. Se as interpretações políticas avaliam o episódio em uma ou outra conjuntura, o certo é que o fato representou consequências em ambos contextos. Os defensores de Paissandu resistiram por mais de um mês, tendo sucumbido no dia 2 de janeiro de 1865. Depois os colorados seguiram com seus aliados rumo a Montevidéu para tomar o poder. Procurando forçar os brasileiros a recuarem para defender suas fronteiras, os blancos do norte do Uruguai cruzaram o rio Jaguarão para atacar o Brasil. Sem alcançar seus objetivos, retiraram-se no dia seguinte, o famoso 27 de janeiro, dia em que a população civil da cidade de Jaguarão expulsou os “castelhanos” (RIZZON, s.d. p. 1053-1054).

a memória dos republicanos. A atual rua Carlos Barbosa em Jaguarão, que passa ao lado da sede central do objeto em estudo, a sede central da Associação Cruzeiro Jaguarense, já foi denominada como Henrique d'Ávila até o ano de 1893. 
O município, assim, especialmente no século XIX, foi uma fronteira instável mas, hoje, apresenta-se como ponto estratégico para integração regional, inclusive com recente reconhecimento da Ponte Internacional Mauá, como patrimônio do MERCOSUL ${ }^{4}$. Nesse contexto, corrobora para pensarmos o patrimônio cultural como fonte para pesquisas e a melhor compreensão do legado histórico e cultural presente na localidade, assim como aos conflitos ou disputas de memória.

Sobre a invasão dos blancos em Jaguarão e nosso trabalho encontramos menção a uma comemoração 30 dias após o fato, portanto, em 27 de fevereiro de 1865 , tal como descrito por Soares $(2015$, p. 113) à partir do correspondente do Diário de Rio Grande, já citando uma comemoração na Sociedade Recreação Familiar Jaguarense, entidade que mais tarde, no ano de 1881 vai ser dissolvida para dar origem ao Club Jaguarense.

Acerca da contextualização de Jaguarão esclarece Miranda (2000), em sua tese Arquitetura e Urbanismo na Fronteira Brasil/Uruguai - O Espaço comercial construído em Jaguarão/Rio Branco (1800-1940), um dado histórico que permace atual.

Nesta fronteira, deu-se uma ocupação do solo, polarizada, ao longo da história de sua formação, em sua maior parte, na grande propriedade pastoril de caráter extensivo. Consequentemente, gerou-se uma região de baixa densidade demográfica, ocupada com poucos municípios. Fenômeno esse que ocorreu tanto no Rio Grande do Sul, como no Uruguai. Constituíram-se municípios com grandes extensões de áreas, concentrando populações em seus centros urbanos, suas sedes (MIRANDA, 2000, p. 390)

Com relação a ocupação da fronteira, para melhor esclarecermos a contextualização histórica e geográfica até aqui descrita, utilizamo-nos de Miranda (2000) quando destaca as relações de influência que interferiram neste território.

Assim a fronteira configura-se como área periférica e, como tal, a cidade de Jaguarão vivia essa situação em duas versões nacionais e outra internacional. Uma pela relação com capital do Estado, Porto Alegre, e outra, a Pelotas, que exercia persuasão e dominação cultural; a terceira, internacional, era relativa à cidade de Montevideo. Jaguarão e Rio Branco estabeleciam dependências que se evidenciavam na economia, na política e na cultura (MIRANDA, 2000, p. 232).

\footnotetext{
${ }^{4}$ Argentina, Brasil, Paraguai e Uruguai assinaram, em 26 de março de 1991, o Tratado de Assunção, para criar o Mercado Comum do Sul (MERCOSUL). O objetivo primordial do Tratado de Assunção é a integração dos Estados Partes por meio da livre circulação de bens, serviços e fatores produtivos, do estabelecimento de uma Tarifa Externa Comum (TEC), da adoção de uma política comercial comum, da coordenação de políticas macroeconômicas e setoriais, e da harmonização de legislações nas áreas pertinentes (cf. MERCOSUL, s.d.).Já a categoria de Patrimônio Cultural do MERCOSUL foi criada através do Decreto 55/2012 do Conselho do Mercado Comum (cf. IPHAN, 2012).
} 
Esclarecidos tais aspectos temporais e espaciais, temos como objetivo geral deste estudo, compreender a trajetória do Clube Jaguarense, importante, a nosso entender, à cidade de Jaguarão, para que se (re)conheçam e revelem os valores associados a este bem cultural enquanto patrimônio material e imaterial, na medida em que há fatos e documentos soterrados/arquivados pelo tempo, por instituições e por indivíduos.

Nosso objeto, então, parte do Club Jaguarense, fundado em 1881, cuja edificação central em estilo eclético foi concluída em 1897; trata-se, sobre a materialidade, de um imóvel destacado do centro urbano do município e, acerca da imaterialidade da entidade em questão, apontamos que os precedentes do Club Jaguarense remontam a 1881, quando foi fundado o Club Jaguarense. No ano de 1975 foi realizada uma fusão com o Esporte Clube Cruzeiro do Sul, fundado em 1924 e deste então, após a fusão associativa e patrimonial guarda a denominação atual como Associação Cruzeiro Jaguarense.

Acerca do caráter elitista da entidade, destacamos a seguir medalha cunhada em Paris no ano de 1897, onde aparece na frente (figura 1) a fachada do imóvel e no verso (figura 2) uma dedicatória de Amacio Nogueira aos consócios, como lembrança da viagem e homenagem ao Club Jaguarense no momento da conclusão de sua edificação.

Fig. 1 Medalha cunhada em Paris (1897) com fachada do Club Jaguarense

Fonte: Disponível em: Arquivo particular de Cleber Carvalho. Acesso em: 2016 
Figura 2 - Verso da Medalha cunhada em Paris (1897)

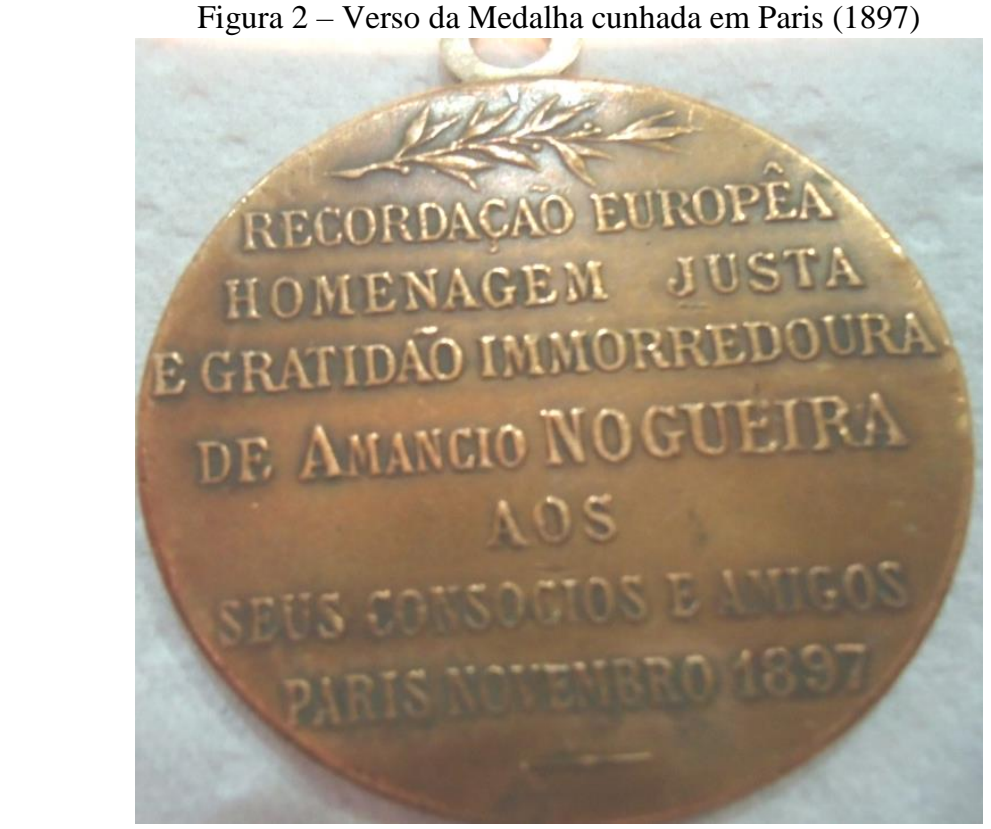

Fonte: Disponível em: Acervo particular de Cleber Carvalho. Acesso em: 2016.

A denominação do clube em estudo, jaguarense, como gentílico do município de Jaguarão, já anuncia a disposição da entidade para a oficialidade, ou seja, trata-se de um clube da elite local. O clube Jaguarense originou-se da Sociedade Recreação Familiar Jaguarense (entidade que funcionou na cidade entre os anos de 1852 a 1881, cf. apontamentos da nossa pesquisa, visto que trabalhos anteriores mencionam sua fundação ao ano de 1857) sob a presidência do Sr. Henrique Francisco d'Ávila, que foi presidente da província de São Pedro do Rio Grande do Sul entre os anos de 1880 e 1881; era natural da freguesia de Herval do Sul/RS quando esta fazia parte de Jaguarão.

A respeito do fundador ${ }^{5}$ do Club Jaguarense, cabe mencionarmos que este já possuía riqueza familiar desde seu nascimento a partir de propriedades familiares (cf. BOTH, 2016). Nessa mesma linha, Soares (2007) comenta que ele era filho do estancieiro Francisco Antônio d'Ávila, revolucionário farroupilha falecido durante um conflito, e de Anna das Chagas d'Ávila, a quem coube sua educação, decidindo, com apoio de um familiar, Irineu Evangelista de Souza, o Visconde de Mauá, enviá-lo para o Rio de Janeiro/RJ onde cursou o colégio Dom Pedro II.

Both (2016), em trabalho recente, aborda a participação de d'Ávila como um dos nomes vinculados à elite imperial na segunda metade do século XIX, sendo um expoente da elite local que saiu da região da fronteira para estudar direito no centro do país e, mais tarde, entrou

\footnotetext{
${ }^{5}$ Em Pelotas/RS, no centro da cidade, a atual Praça Cipriano Barcelos já foi denominada como Praça Henrique Francisco d'Ávila (cf. PELOTAS, 2012).
} 
nas fileiras dos políticos liberais exercendo inúmeros cargos de natureza civil e militar ao longo de sua carreira, até o desfecho do regime monárquico em 1889.

Este conceito de elite proposto pela autora é apropriado para este estudo. Nas palavras da autora:

\begin{abstract}
Desse modo, a definição que adotamos de elite é operacional e abarca os indivíduos que atingiram o topo da hierarquia social no município de Jaguarão, através da ocupação de "posições-chave", que lhes conferiam "status, poder e riqueza" e privilégios nas relações sociais, uma vez que dispunham de recursos materiais e simbólicos que não estavam acessíveis a maioria da população [grifos da autora] (BOTH, 2016, p. 19).
\end{abstract}

Nesse entendimento de elite, reiteramos a trajetória de d'Ávila como proeminente em função dos cargos por ele ocupados, conforme salienta Both (2016), acrescendo ainda, outro nome importante no período imperial, também com relevância em Jaguarão, que foi o Conselheiro Diana ${ }^{6}$.

Ao longo de suas carreiras foram eleitos vereadores, deputados provinciais e gerais, foram nomeados Ministros do Império (Ávila na pasta de Agricultura, Comércio e Obras Públicas em 1883 e Diana na pasta de Estrangeiros, em 1889) e Henrique d'Ávila foi também Senador por um longo período, além de Presidente da Província do Rio Grande do Sul (1880) e do Ceará (1889) (BOTH, 2016, p. 52).

Henrique Francisco d'Ávila, advogado formado na academia de direito de São Paulo/SP em 1855, no primeiro curso fundado no Brasil por decreto imperial pelo Imperador Dom Pedro I, em 1827. A instituição foi criada no mesmo ato que a faculdade de Olinda/PE, ambas como "Cursos de Sciencias Jurídicas e Sociaes". Este fato trata-se de um marco na criação das novas elites nacionais após o processo de Independência brasileira ocorrida em 1822, pois até este momento era necessário ir a Coimbra, em Portugal, normalmente, para graduar-se. Sobre o contexto da independência melhor esclarece Carvalho (2002).

\footnotetext{
${ }^{6}$ José Francisco Diana era advogado formado pela academia de direito de São Paulo, em 1868. Em 1869, foi presidente do partido liberal em Jaguarão por indicação de Henrique Francisco d’Ávila que foi seu vice (cf. APONTAMENTO PARA UMA MONOGRAFIA EM JAGUARÃO, 1912). Foi deputado provincial (1873/89) e deputado geral (1872/89). Também, foi o último Ministro dos Negócios Estrangeiros (1889) do regime monárquico equivalente hoje ao de Ministro de Relações Exteriores. Exerceu ainda a função de professor de Carlos Barbosa Gonçalves. E após o término da Monarquia, ficou estabelecido em Montevideo. Atualmente, a rua da Universidade Federal do Pampa (Unipampa), em Jaguarão, chama-se Conselheiro Diana. E antes da proclamação da república, até o ano de 1893, Diana estava onde atualmente é a Rua Júlio de Castilhos. Ele casou-se com Amélia Leopoldina Côrrea, filha de Faustino Corrêa e Maria Carolina Corrêa, irmã da Minervina Carolina Corrêa. Especificamente, no contexto deste trabalho, ele foi identificado como membro da diretoria da Sociedade Recreação Familiar Jaguarense, no ano de 1875. Fez parte dos fundadores do Club Jaguarense em 1881, compondo a Comissão Fiscal. Em 1884, aparece entre os fundadores do Club Harmonia (cf. Botelho, 2016). E atuou como mediador durante a fusão efêmera entre o Club Jaguarense e a Sociedade Cassino Jaguarense.
} 
Ao proclamar sua independência de Portugal em 1822, o Brasil herdou uma tradição cívica pouco encorajadora. Em três séculos de colonização (1500-1822), os portugueses tinham construído um enorme país dotado de unidade territorial, linguística, cultural e religiosa. Mas tinham também deixado uma população analfabeta, uma sociedade escravocrata, uma economia monocultora e latifundiária, um Estado absolutista. À época da independência, não havia cidadãos brasileiros, nem pátria brasileira(CARVALHO, 2002, p.18).

Sobre a importância do ensino superior para a formação das elites nacionais Anderson (2008) destaca que o ensino superior na colônias espanholas já seria bem anterior, em oposição ao Brasil, proibido por Portugal, de tal modo que este seria também um dos elementos constituinte nos processos de independência nas colônias espanholas já como repúblicas no começo do século XIX.

De acordo com Silva (s.d.), para ingressar no curso em São Paulo/SP eram estabelecidos critérios. Na sua explicação:

No início, os estudantes eram admitidos mediante apresentação de certidão de idade (com um mínimo de 15 anos completos) e aprovação em exames de Língua Francesa, Gramática Latina, Retórica, Filosofia Racional e Moral e Geometria. Depois de cinco anos de curso, recebiam o grau de "bacharéis formados" [grifo da autora] (SILVA, s.d., p.2).

Vargas (2007) assinala o seu temperamento como "um homem de talento, orador imaginoso e temido polemista" (AQUILES, 1976 ap. VARGAS, 2007, p. 249). Na obra Apontamentos para uma monografia em Jaguarão (1912), descreve-se a sua dificuldade em tomar posse como presidente da Câmara pelo partido liberal e que relatara, inclusive, este fato para o Imperador Dom Pedro II, quando passou em Jaguarão no período da guerra do Paraguai, ao retornar de Uruguaiana, no ano de 1868. O fato é narrado de tal modo que a contenda foi decidida a seu favor, após a conversa com o Imperador, tendo em vista que havia sido designado como vereador para acompanhá-lo pela cidade, incluindo a ida ao Cerro da Pólvora.

Logo, no ano seguinte, 1869, d'Ávila funda o diretório do Partido Liberal, indicando Diana como presidente da agremiação e ele permanecendo como vice. Vargas (2007) relata que d'Ávila manteve sociedade em uma empresa bancária com Diana, e descreve que no desfecho de sua vida faleceu pobre em virtude de dívidas contraídas com empresários jaguarenses. Sobre o seu falecimento, Franco (s.d.) escreve que ocorreu em 05/06/1903, em Porto Alegre/RS.

Observando o que foi relatado, sobre a circulação da elite, no século XIX, constatamos a relevância dos espaços de sociabilidade, e em especial os bailes, que é a principal atividade 
desenvolvida em nosso objeto de estudo, o Clube Jaguarense. Martins (2007), escreve que "além do convívio dos espaços formais da política, os membros da elite política imperial encontravam-se em bailes, cafés e hotéis que todos frequentavam, onde a 'vida social misturava-se à política"” [grifo da autora] (MARTINS, 2007 ap. BOTH, 2016).

\section{Metodologia}

A pesquisa é de caráter qualitativa tal como descreve Gray (2012), ou seja, “o papel do pesquisador é obter um panorama profundo, intenso e 'holístico' do contexto em estudo, muitas vezes envolvendo a interação dentro das vidas cotidianas de pessoas, grupos, comunidades e organizações" [grifo do autor] (p. 135). Nesse sentido, diferentemente da pesquisa quantitativa, os dados coletados são abertos a múltiplas interpretações e, assim, as reflexões do próprio pesquisador sobre suas ações e suas observações tornam-se parte dos dados. Nessa abordagem, a preocupação está na observação e reflexão do nosso arquivo.

Portanto, o clube, a nosso ver, pela sua importância e longevidade, aqui brevemente apresentadas, como chega no século atual com atividades bastante reduzidas, incluindo o risco de fechamento ou interrupção? Este problema, que envolve o declínio e interdição das atividades do clube jaguarense, ou melhor da Associação Cruzeiro Jaguarense, aponta para a necessidade desta reflexão, considerando que o Clube é um bem cultural relevante, entrelaçado com a história e as memórias do município e dos moradores de Jaguarão, e eventualmente ponto de apoio para memória dos relatos de viagem, aos que passavam pela cidade.

\section{Discussão}

Encontramos as representações iconográficas do objeto de estudo, muito próximo do que aparece hoje em sua fachada em um postal, conforme segue (figura 3 e 4) datado de 1908, encaminhado para a Bélgica pelo Cônego Godofredo da Ordem dos premostatenses. 
Figura 3 - Cartão postal do Club Jaguarense enviado em 1908 para Bélgica

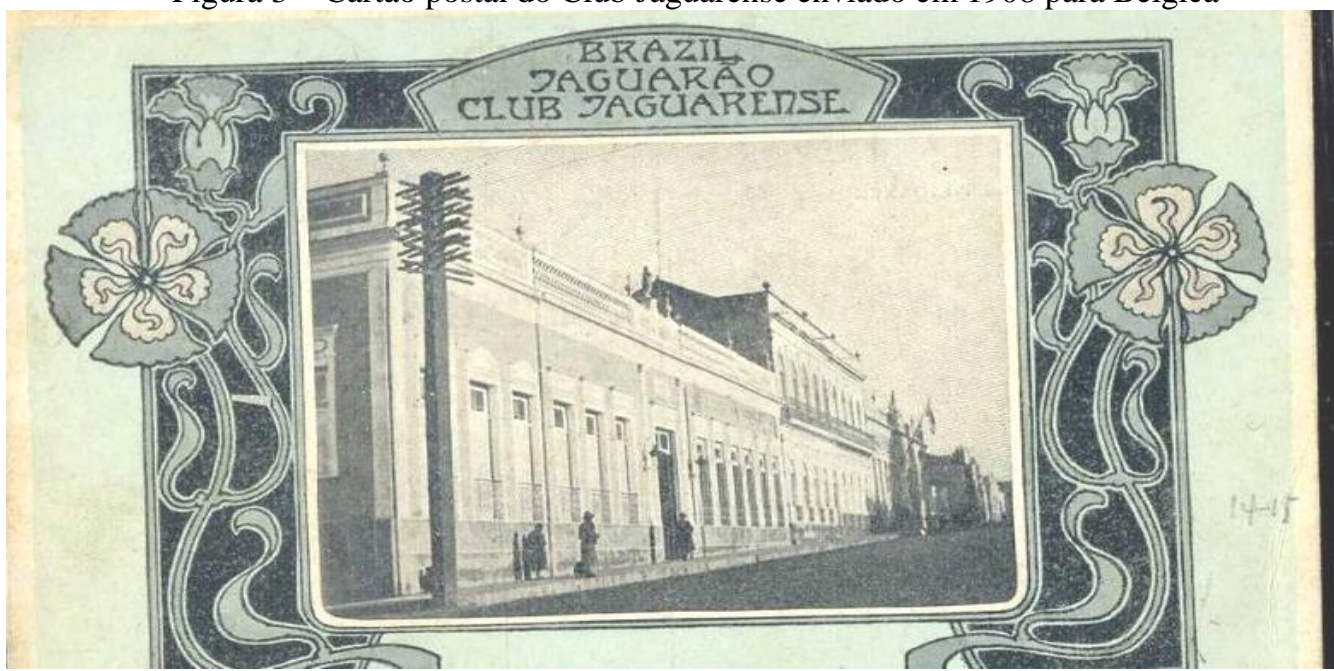

Fonte: Disponível em: <https://www.delcampe.net/en_GB/collectables/>. Acesso em: 07/07/2016.

Figura 4 - Verso do Cartão postal do Club enviado para Bélgica (1908)

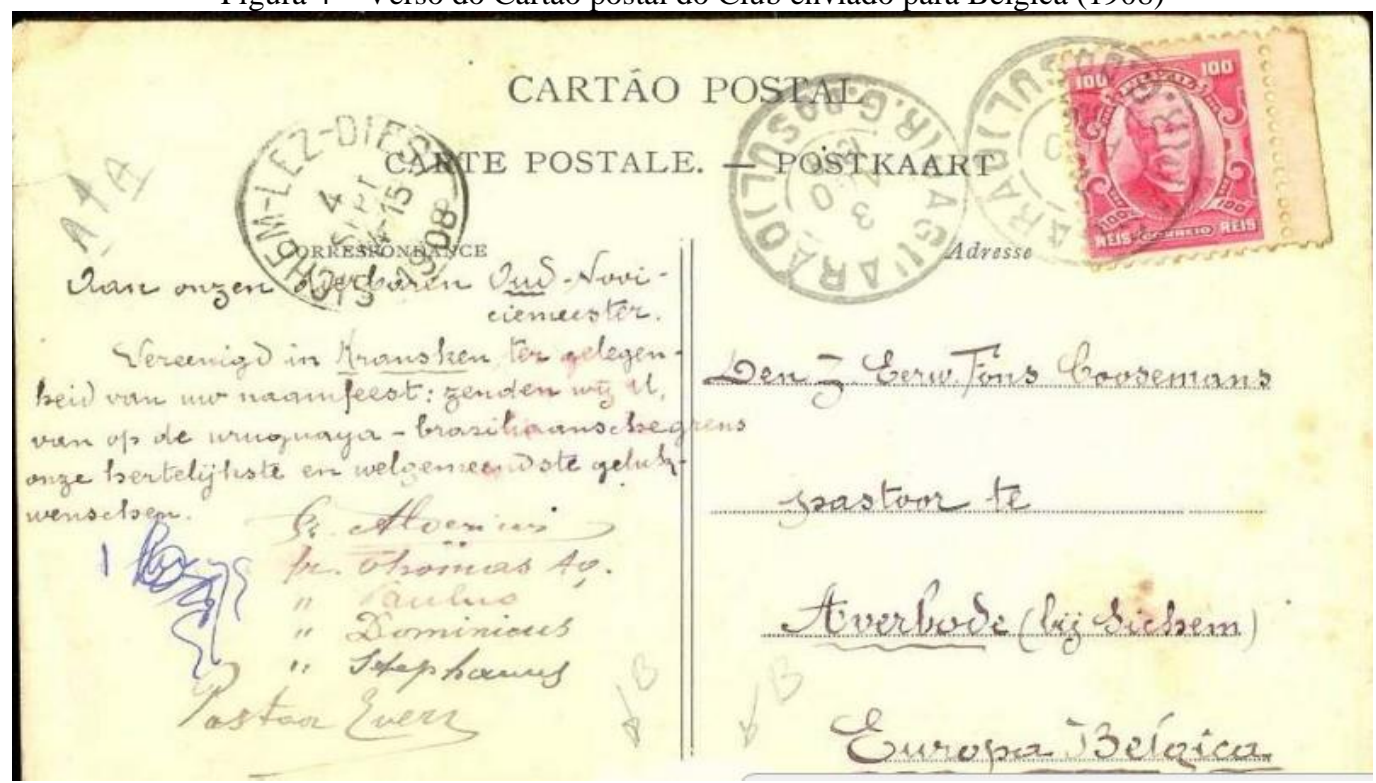

Fonte: Disponível em: <https://www.delcampe.net/en_GB/collectables/>. Acesso em: 07/07/2016.

Aparece, portanto já o Club Jaguarense, como um exemplar representativo no espaço urbano do município de Jaguarão no alvorecer do século XX, questão mantida até os dias atuais, bem como um apoio de memória, aos que passam pela cidade, como neste caso, por religiosos que atuaram na cidade.

Sobre a sede central da Associação Cruzeiro Jaguarense, ressaltamos que o imóvel ${ }^{7}$ foi tombado pelo IPHAN, no ano de 2011. O exemplar é classificado como de preservação rigorosa no conjunto histórico e paisagístico do município de Jaguarão. O imóvel está localizado no Largo das Bandeiras, esquinada rua Carlos Barbosa, na zona central da

\footnotetext{
${ }^{7}$ O clube possui além da sede central uma sede campestrre com piscina e estádio de futebol, bens oriundos da fusão com o clube de futebol "Esporte Clube Cruzeiro", no ano de 1975.
} 
cidade.Abaixo,apresentamos a fachada central do clube em estudo. O imóvel está interditado para uso, pois sofreu desabamento da sua cobertura no dia 01/11/2011. Naquele momento foi realizado primeiro um escoramento do imóvel pela municipalidade, e após um salvamento emergencial $^{8}$ através do IPHAN ${ }^{9}$ para recompor a cobertura, visto tratar-se de bem protegido pelo tombamento federal. Tal fato, culmina na questão que apontamos como determinante neste estudo, já que parece que a entidade está encontrando dificuldades em reergue-se e manter suas atividades de forma plena. Esta proposição abarca-se na situação que encontramos quando foi realizado o trabalho de campo, no ano de 2016, em que o prédio se encontrava completamente fechado, de tal modo, que a ausência de usos e de manutenção também estavam contribuindo para a sua deterioração. Diante da situação, existe um projeto em andamento para restauração do imóvel ${ }^{10}$, com valor estimado em $\mathrm{R} \$ 3.500 .000,00^{11}$ (três milhões e quinhentos mil reais).

\footnotetext{
${ }^{8}$ Na placa da obra aparece: "Estabilização emergencial do Clube Jaguarense; PAC - Programa de Aceleração do crescimento Cidades Históricas; Município: Jaguarão RS; Valor total da obra: R\$ 447.704,24 (quatrocentos e quarenta e sete mil reais, setecentos e quatro reais e vinte e quatro centavos); Agentes participantes: Governo Federal - País Rico é País sem Pobreza; Constam:Ministério da Cultura, Ministério da Educação, IPHAN, IPHAE RS e Prefeitura Municipal de Jaguarão".

9 SUPERINTENDÊNCIA NO RIO GRANDE DO SUL.EXTRATO DE CONTRATO No 9/2011 UASG 343012. $\mathrm{N}^{\circ}$ Processo: 01512002265201104.DISPENSA $\mathrm{N}^{\circ}$ 13/2011 Contratante: INSTITUTO DO PATRIMONIO HISTORICO-E ARTISTICO NACIONAL. CNPJ Contratado: 06939632000100. Contratado : ARQUIUM - CONSTRUCOES E RESTAURO -LTDA.. Objeto: Contratação de serviços de pessoa jurídica para realização de estabilização emergencial em edificação tombada denominada Clube Jaguarense, localizada em Jaguarão/RS. Fundamento Legal: Lei 8666/93 . Vigência: 14/12/2011 a 14/05/2012. Valor Total: R \$447.704,24. Fonte: 100000000 - 2011NE800129. Data de Assinatura: 14/12/2011.(SICON - 14/12/2011) 343026-40401-2011NE800022 (Cf. http://www.buscaoficial.com/c/diario/cx0Ddg9Kp/ acesso em 30/07/2017)

${ }^{10}$ INSTITUTO DO PATRIMÔNIO HISTÓRICO E ARTÍSTICO NACIONAL PORTARIA N 383, DE 20 DE AGOSTO DE 2013 A PRESIDENTA DO INSTITUTO DO PATRIMÔNIO HISTÓRICO E ARTÍSTICO NACIONAL, no uso das atribuições que lhe confere o art. 21, Inciso V, anexo I, do Decreto $\mathrm{n}^{\circ}$ 6.844, de 07 de maio de 2009, considerando o disposto na Portaria $\mathrm{n}^{\circ} .92$, de 05 de julho de 2012, publicada no DOU de 09 de julho de 2012,Considerando o processo seletivo iniciado em 30/01/2013 (Proc. 01450.004028/2013-11), para apresentação de propostas de intervenções no âmbito do PAC Cidades Históricas, pelos Chefes dos Poderes Executivos Municipais e/ou Estaduais de 44 municípios brasileiros com patrimônio histórico tombado em nível federal,Considerando que o PAC Cidades Históricas é segmento do Eixo Comunidade Cidadã do PAC 2, resolve:Art. $1^{\circ}$ Tornar públicas as intervenções selecionadas no âmbito do PACCidades Históricas, nos termos do Anexo I.Art. $2^{\circ} \mathrm{O}$ início da execução das intervenções relacionadas no Anexo I está condicionada à apresentação e aprovação pelo Iphan do material técnico correspondente.Art. $3^{\circ}$ Os recursos disponibilizados serão oriundos do Orçamento Geral da União (OGU), no âmbito da segunda fase do Programa de Aceleracao do Crescimento - PAC 2.Art. $4^{\circ}$ Esta Portaria entra em vigor na data de sua publicação. JUREMA MACHADO. Consta no anexo os seguinte projetos em Jaguarão: Finalização da restauração da Antiga Enfermaria Militar - Centro de Interpretação do Pampa - Unipampa;Finalização da restauração do Teatro Esperança; Restauração da Igreja Matriz do Divino Espírito Santo; Restauração do Mercado Público Municipal; Restauração do Antigo Fórum - Casa de Cultura; Restauração da Antiga Inspetoria Veterinária; Restauração do Casarão da Prefeitura Municipal; Jaguarão Requalificação da Praça Dr. Alcides Marquese Largo das Bandeiras; Restauração do Casarão do Clube Jaguarense; Restauração do Casarão Clube Social 24 de Agosto; Restauração do Cine Regente. Cf.( https://www.jusbrasil.com.br/diarios/58125488/dousecao-1-22-08-2013-pg-5?ref=previous_button acesso em 30/07/2017).

${ }^{11} \mathrm{O}$ clube está elencado como a nona prioridade entre onze bens listados. Cf.( Processo Prefeitura Municipal 2771/2014-21927) aberto em 22/04/2014 denominado PAC Cidades Históricas - Clube Jaguarense. Estão previstos $\mathrm{R} \$ 500,000,00$ (quinhentos mil reais) para estudos e projeto e 3.500,000,00(três milhões e quinhentos
} 
Para dar continuidade na contextualização do objeto de estudo, no centro urbano do município de Jaguarão, apresentamos outra imagem, captada com equipamento denominado drone visto como foto aérea (Figura 5). Nela é possível identificarmos o clube do alto, ampliando a visualização da imagem anterior: à esquerda, salão principal, já com o telhado recuperado, por isso, tonalidade mais clara, e ao lado, direito, no salão menor, com cobertura em tom mais escuro, que atualmente está bastante deteriorado.

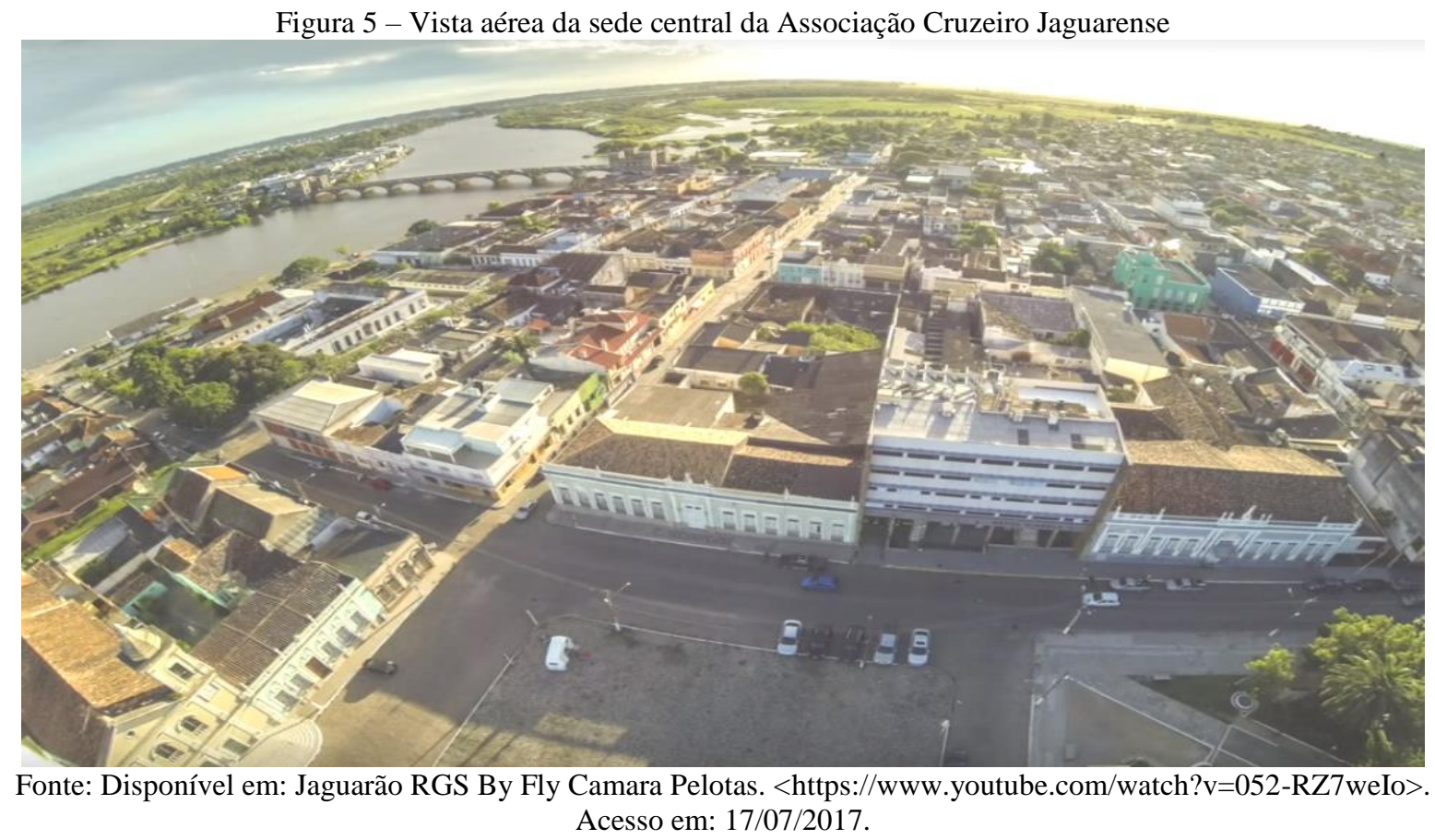

Nesta imagem é possível identificarmos a extensão do imóvel e podemos visualizar ainda os arredores do prédio, na sua frente o largo das bandeiras, e ao seu lado, o Hotel Sinuelo que segue do Clube Harmonia Jaguarão, em frente à Praça Alcides Marques existem proximidades e distanciamentos entre a Associação Cruzeiro Jaguarense com o Clube Harmonia Jaguarão, outro clube da elite local, descrito em trabalho recente por Isadora Botelho (2016).

Também podemos identificar na imagem em questão, a ponte internacional Mauá, localizada à esquerda do Clube, ao fundo, sobre o Rio Jaguarão. Neste conjunto visual, ficam evidenciados os valores que justificaram o tombamento do centro histórico do município através do IPHAN ${ }^{12}$, que é especialmente a homogeneidade da sua ambiência urbana, na

mil reais) para a obra. O tempo estimado para a conclusão da obra ao acessar os recursos esta estimado em 25(vinte e cinco) meses.

${ }^{12}$ INSTITUTO DO PATRIMÔNIO HISTÓRICO.E ARTÍSTICO NACIONAL AVISOS DE TOMBAMENTO DEFINITIVO.O INSTITUTO DO PATRIMÔNIO HISTÓRICO E ARTÍSTICO NACIONAL - IPHAN 
maior parte assobradada com grande número de exemplares arquitetônicos que remetem ao final do século XIX e primeiras décadas do século XX. O tombamento do centro urbano do município foi realizado com base em dois valores principais: um que se refere ao paisagístico, conforme verificamos na imagem, e outro que se refere ao valor histórico, conforme já elencado, tendo em vista a importância da localidade no contexto das disputas e a formação territorial e histórica no século XIX. A ponte Internacional Mauá também tombada pelo IPHAN $^{13}$ foi acrescido o valor artístico, de artes aplicadas.

O patrimônio cultural do clube abarca, assim, os aspectos materiais e imateriais da entidade, de tal modo que norteia a presente reflexão. E o patrimônio cultural é um tema emergente dos séculos XX e XXI, conforme trabalham diversos autores, trata-se de categoria social e política situada no interstício entre o espaço público e o espaço privado. Trata-se, nessa perspectiva, de uma forma de proteção de bens culturais por ação estatal em benefício público. Portanto, o patrimônio cultural abarca a dimensão simbólica e de representação social que comporta o bem em estudo, seja a associação Cruzeiro Jaguarense.

Logo, esta instituição possui vínculo com representação de nação, o país, porque tratase de um patrimônio nacional, mas, também, possui uma dimensão de proximidade, na medida em que o proprietário do bem, a Associação Cruzeiro Jaguarense, e as pessoas que estão mais vinculadas a ele possuem relação de identidade e de afetividade, assim como os moradores da cidade, muitos habituados com a sua presença na paisagem urbana, percebendoo como suporte de memórias, pois lá já passaram ou, pelo menos, ouviram falar de fatos ligados à entidade.

Nessa dimensão de proximidade, o Clube cedia, gratuitamente ou em forma de locação, o seu espaço para uso da comunidade jaguarense. Dentre outras atividades, podemos

dirige-se a todos os interessados para lhes COMUNICAR que ocorreu o tombamento definitivo do Conjunto Histórico e Paisagístico de Jaguarão, Município de Jaguarão, Estado do Rio Grande do Sul, por meio do Processo n. ${ }^{\circ}$ 1.569-T-08 (Processo n. ${ }^{\circ}$ 01512.000089/2008-62), o qual foi inscrita no Livro do Tombo Histórico, volume III, fls. 53/57, número de inscrição: 615 e no Livro do Tombo Arqueológico, Etnográfico e Paisagístico, volume II, fl. 76/79, número de inscrição: 163. Amparo legal: Decreto-Lei no 25 , de 30 de novembro de 1937, Portaria $n^{\circ}$. 11, de 11 de setembro de 1986 e Decreto $\mathrm{n}^{\circ}$. $\underline{6.844}$, de 07 de maio de 2009.(Cf. https://www.jusbrasil.com.br/diarios/51086831/dou-secao-3-21-02-2013-pg-11 acesso em 30/07/2017).

${ }^{13}$ INSTITUTO DO PATRIMÔNIO HISTÓRICO. E ARTÍSTICO NACIONAL AVISO. O INSTITUTO DO PATRIMÔNIO HISTÓRICO E ARTÍSTICO NACIONAL - IPHAN dirige-se a todos os interessados para lhes COMUNICAR que ocorreu o tombamento definitivo da Ponte Internacional Mauá, Município de Jaguarão, Estado do Rio Grande do Sul, por meio do Processo n. ${ }^{\circ}$ 1.570-T-09 (Processo n. ${ }^{\circ}$ 01512.000067/2008-01), a qual foi inscrita no Livro do Tombo Histórico, volume III, fls. 41 a 43, número de inscrição: 607; no Livro do Tombo Arqueológico, Etnográfico e Paisagístico, volume II, fls. 72 e 73, número de inscrição: 157 e no Livro do Tombo das Artes Aplicadas, volume I, fls. 02 a 05, número de inscrição: 05. Amparo legal: Decreto-Lei $\mathrm{n}^{\circ} . \underline{25}$, de 30 de novembro de 1937, Portaria $\mathrm{n}^{\circ} .11$, de 11 de setembro de 1986 e Decreto $\mathrm{n}^{\mathrm{o}}$. 6.844, de 07 de maio de 2009.JUREMA MACHADO.Presidenta do Instituto. (Cf. https://www.jusbrasil.com.br/diarios/43660692/dou-secao-3-28-11-2012-pg-21 acesso em 30/07/2017). 
rememorar a primeira festa de formatura da Unipampa, realizada no ano 2011 e ainda seminários de formação docente promovidos pela municipalidade em conjunto com a universidade (figura 6). Neste sentido, é importante ressaltarmos que, embora a entidade seja de caráter privado, identificamos permeabilidade para atividades de natureza pública. O clube embora ceda seu espaço, comporta um aspecto de elite, pois depende normalmente de associação e pagamento de mensalidades para acesso as suas dependências.

Exemplificamos o exposto, sobre as atividades de finalidade pública ou institucional, com a imagem do Seminário Docência em movimento realizado no dia 01/08/2011, portanto em período próximo da sua interdição em novembro do mesmo ano.

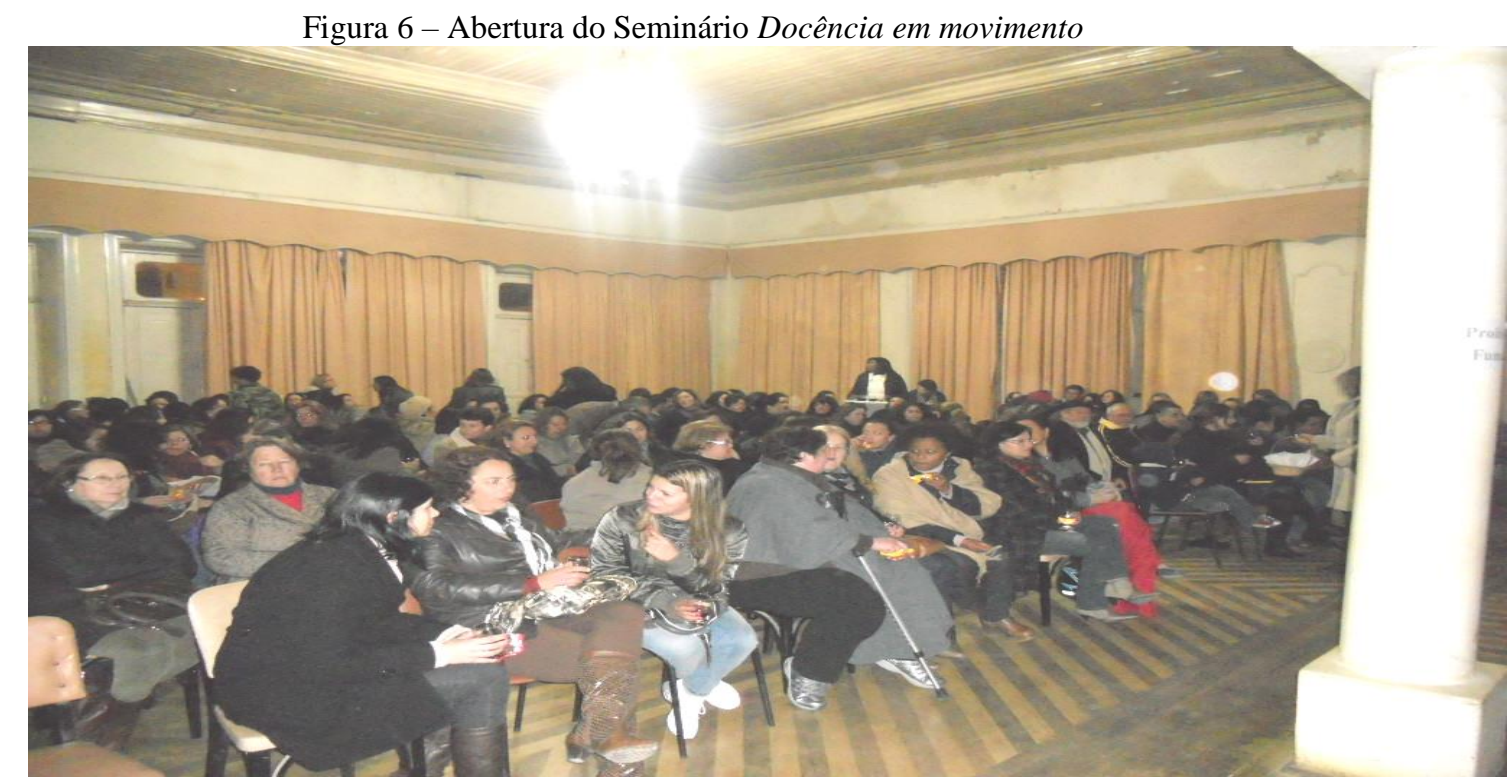

Fonte: Disponível em:<http://brfatima.blogspot.com.br/>. Acesso em: 17/07/2017.

Algumas oficinas realizadas no Seminário aconteceram no salão principal do Clube ${ }^{14}$, outras aconteceram na Unipampa; isto mostra a relação da entidade com outras instituições do município, além dos tradicionais bailes, jantares e festas carnavalescas, dentre outras atividades que caracterizam o funcionamento do objeto pesquisado.

\section{Conclusões}

Portanto, a Associação Cruzeiro Jaguarense, foi identificada como uma entidade com função social comunitária importante, face aos seus usos e ao reconhecimento da própria sociedade como legitimadora da sua atuação enquanto um patrimônio comum aos jaguarenses. Além disso, ficou destacado no trabalho que o bem cultural possui proteção

\footnotetext{
${ }^{14}$ Oficina 3 - Expressão Corporal Profa. Ms. Maria Falkembach (UFPEL)e Oficina 10 - Arte e Música Prof. Dr. Leandro Maia (UFPEL) foram oficinas realizadas no clube (Cf. Blog da professora Fátima).
} 
garantida como integrante do conjunto histórico e paisagístico, tombado pelo IPHAN. No entanto, a sua atual interdição, desde 2011, bem como o declínio dos associados, corrobora para a realização deste trabalho.

Por fim, encontramos diversas relações entre a história e a memória que podem ser percebidas através do estudo realizado na Associação Cruzeiro Jaguarense, que possui sua origem no primeiro clube social da elite local fundado em 1881 sob a denominação de Club Jaguarense, destacando sobretudo neste trabalho, na sua origem e fundação por lideranças vinculadas ainda no período do Brasil Imperial.

A atual denominação como associação, deriva da fusão com o time de futebol, Esporte Clube Cruzeiro do Sul (fundado em 1924) realizada no ano de 1975. E de forma mais remota ainda, o Club Jaguarense, foi identificado como herdeiro da Sociedade Recreação Familiar Jaguarense, entidade da elite local que funcionou entre os anos de 1852 a 1881, quando terminou para dar origem ao Club Jaguarense.

\section{Referências}

ANDERSON, B. Comunidades imaginadas: reflexões sobre a origem e a difusão do nacionalismo. São Paulo: Companhia das Letras, 2008.

BLOG da professora Fátima. Docência em movimento. http://brfatima.blogspot.com.br/ acesso em 13/07/2017.

BOTELHO, I. S. Entre danças e Tramas: os espaços de sociabilidade e os fundadores do Clube Social Harmonia Jaguarão (1882-1890). 2016. Trabalho de Conclusão de Curso, Licenciatura em História. Universidade Federal do Pampa (Unipampa), Jaguarão, 2016.

BOTELHO, I. S. Entre danças e Tramas: os espaços de sociabilidade e os fundadores do Clube Social Harmonia Jaguarão (1882-1890). 2016. Trabalho de Conclusão de Curso, Licenciatura em História. Universidade Federal do Pampa (Unipampa), Jaguarão, 2016.

BOTH, A. C. A trama que sustentava o Império: mediação entre as elites locais e o Estado Imperial Brasileiro (Jaguarão, segunda metade do século XIX). 2016. Porto Alegre.

Dissertação de Mestrado em História. Pontifícia Universidade Católica de Porto Alegre.

CARVALHO, J. M. Cidadania no Brasil. O longo Caminho. $3^{\mathrm{a}}$ ed. Rio de Janeiro:

Civilização Brasileira, 2002.

EU, Conde D'. Viagem Militar ao Rio Grande do Sul. Companhia Editora Nacional: São Paulo, 1936). Fonte: Disponível em:<http://www.brasiliana.com.br/obras/viagem-militar-aorio-grande-do-sul acesso em 14/07/2017>. Acesso em: 21/07/2017.

CUSTÓDIO, L. A. et al. Roteiros de Arquitetura da Costa Doce - Rio Grande do Sul. Porto Alegre: Editora SEBRAE, 2009. 
ENSSLIN, L. C. Ecletismo arquitetônico em Jaguarão: um estudo de caso (1870-1940). 2005. 115 f. Dissertação, Mestrado em Arquitetura. Universidade Federal do Rio Grande do Sul. Porto Alegre, 2005. Fonte: Disponível em:

<https://www.lume.ufrgs.br/bitstream/handle/10183/4458/000501515.pdf?sequence=1>. Acesso em: 25/07/2017.

FRANCO, S. da C. Gaúchos na academia de Direito de São Paulo no século 19. Revista Justiça e História. s.d. Fonte: Disponível em:

<https://www.tjrs.jus.br/export/poder_judiciario/historia/memorial_do_poder_judiciario/mem orial_judiciario_gaucho/revista_justica_e_historia/issn_16765834/v1n1_2/doc/04._Sergio_Fr anco.pdf>. Acesso em: 21/05/2017.

GRAY, D. Pesquisa no mundo real. 2. Ed. Porto Alegre: Penso, 2012.

INSTITUTO BRASILEIRO DE GEOGRAFIA E ESTATÍSTICA - IBGE. Jaguarão. Acesso em 07/08/2016. www.ibge.gov.br.

INSTITUTO DO PATRIMÔNIO HISTÓRICO E ARTÍSTICO NACIONAL - IPHAN. Dossiê para o tombamento do centro histórico do município de Jaguarão. Fonte: Disponível em: <http://wp.ufpel.edu.br/sigwebjaguarao/files/2014/09/Dossi\%C3\%AA-TombamentoJaguar\%C3\%A3o.pdf $>$. Acesso em: 14/07/2017.

INSTITUTO DO PATRIMÔNIO HISTÓRICO E ARTÍSTICO NACIONAL - IPHAN. Iphan.gov.br acesso em 24/11/2017.

JAGUARÃO. Apontamentos para um monografia em Jaguarão.: 2. Exposição AgroPecuária. Porto Alegre: Intendência Municipal de Jaguarão, 1912.

JAGUARÃO. Processo Prefeitura Municipal 2771/2014-21927 aberto em 22/04/2014 denominado PAC Cidades Históricas - Clube Jaguarense.

JUSBRASIL. https://www.jusbrasil.com.br/home acesso em 30/07/2017

MARTINS, R. D. A ocupação do espaço na fronteira Brasil-Uruguai: a construção da cidade de Jaguarão. 2001. 271 f. Tese, Doutorado em Histórias Especializadas. Universidade Politécnica da Catalunha, Espanha, 2001. Fonte: Disponível em:

<http://upcommons.upc.edu/handle/2117/93390>. Acesso em: 25/07/2017.

MIRANDA, W. M. Arquitetura e urbanismo na fronteira Brasil / Uruguai: espaco comercial construido em Jaguarao / Rio Branco (1800-1940). Pelotas, 2000. 419f. Tese (Doutorado em Integracao Regional) - Universidade Federal de Pelotas.

PELOTAS. Prefeitura Municipal de Pelotas. Praça Cipriano Barcelos.

http://www.pelotas.rs.gov.br/noticias/detalhe.php?controle=MjAxMi0wNi0yMA==\&codnotic $\underline{i a=31285}$ acesso em 13/07/2017

RIZZON, C. Tempos e lugares do regionalismo. Fonte:

http://ebooks.pucrs.br/edipucrs/Ebooks/Web/978-85-397-0198-8/Trabalhos/15.pdf acesso em $29 / 07 / 2017$ 
RODRIGUES, C. R. Sociedade Harmonia Jaguarão - um século de história. Cadernos Jaguarenses. Revista do Instituto Histórico e Geográfico de Jaguarão/Prefeitura municipal de Jaguarão. Jaguarão, 1990. p. 63-79.

SOARES, E. Á. de S. Edição comemorativa ao Sequicentenário da Resistência ao Ataque Blanco a Jaguarão em 27 de janeiro de 1865. Porto Alegre: Evangraf, 2015.

SILVA, E. S. Ensino de Direito no Brasil: perspectivas históricas gerais. s.d. Fonte: Disponível em: <http://www.scielo.br/pdf/pee/v4n1/v4n1a08 acesso em 21/05/2017>. Acesso em: 25/07/2017.

VARGAS, J. M. Entre a paroquia e a corte: uma análise da elite política do Rio Grande do Sul (1868-1889). 2007. 279 f. Dissertação, Mestrado em História. Universidade Federal do Rio Grande do Sul, Porto Alegre, 2007. Fonte: Disponível em: <http://observatoryelites.org/wp-content/uploads/2011/11/Vargas-Paroquia-Corte-UFRGS.pdf >. Acesso em: 25/07/2017. 